\title{
Storytelling through Art: Teaching the History of Indonesia with Video Games
}

\author{
Josua Ng \\ Game Application \& Technology Department, School of Computer Science, Bina Nusantara University, \\ Jakarta, Indonesia \\ Email: josua.ng@binus.ac.id
}

How to cite this paper: Ng, J. (2019). Storytelling through Art: Teaching the History of Indonesia with Video Games. Art and Design Review, 7, 29-40. https://doi.org/10.4236/adr.2019.71004

Received: January 7, 2019

Accepted: January 30, 2019

Published: February 2, 2019

Copyright @ 2019 by author(s) and Scientific Research Publishing Inc. This work is licensed under the Creative Commons Attribution International License (CC BY 4.0).

http://creativecommons.org/licenses/by/4.0/

\begin{abstract}
Games nowadays have been associated with the decline of a child's academic performance. Whether this is true or not, it remains to be seen, as there's no link that has been found between the two after several researchers conducted their own research. This paper's aim is to discuss whether the game art motivates the user to find out more about the topic that are brought up in the said game, which in this case is the history of Indonesia, specifically from the periods of just before and during the Japanese Occupation to the Declaration of Indonesia's Independence in 1945. Aside from accurate depiction of objects, buildings or events, another question posed is whether the chosen art style conveys the atmosphere of the situation depicted, and if it helps with the storytelling of the game.
\end{abstract}

\section{Keywords}

History, Indonesia, Video Game, Educational, Storytelling, Game Art, Art Style, Literature Study, Data Analysis

\section{Introduction}

The main form of education in the present era is synonymous with books, typically ones with few pictures and a lot of text. However, the children that are currently growing up in an era where they are heavily reliant on technology, especially the Internet, finds the traditional method of studying with books to be boring (Charsky \& Ressler, 2011). Instead of effectively being able to learn from the books, they find it more of a chore, hence the decrease in interest of learning the subject in question, in which for the subject of this paper is History (Erhel \& Jamet, 2013). Hence, various solutions were offered, and one of the most forefronts at it is educational video game (Peirce, Conlan, \& Wade, 2008). The typi- 
cal issue for educational video games, however, is the fact that only some were clearly invested in terms of basic video game development: plot, gameplay, art and sound (Yue \& Zin, 2009). This paper aims to discuss the art of the said educational video game, and whether it could help in the storytelling or not.

When most people say about graphics of games, they usually refer to the style of the graphic used in the game, or in other words, the style of the game art. The short definition of game art is basically an art that's inspired by digital games (Apperley, 2013). Take for example: Battlefield 1 . While most would say that it's highly-realistic, it's because the art style used in the game is a style called Realistic, which is one example of the several art styles that are commonly used in various mediums that also includes video games.

When drawing a game art, the first thing that must be considered is the art style. Depending on how the developers want to portray the subject of their choosing, certain art styles are better at depicting said portrayals. Once the art style has been chosen and the sketch has been made, the next step would be choosing what colors that will be used to bring the art to life, so to speak. The colors will affect the stimuli of the said art will have on the viewers. Dark colors for portraying a grim battle, a near-despairing situation where hope is the only thing to sustain the characters in that fight, as they fought under the darkened sky, for example. After the colors has been picked \& applied to the sketch (in this case the basic colors), the next step would be to see if the draft is in line with what the rest of the devs had in mind, especially the storywriter and the game designer. If it were to be rejected, then going back to the drawing board would be the next step. But if it's approved, then the next stage would be refining the sketch. Refining the sketch, in other words, drawing a proper art instead of a sketch that's basically a draft. In this stage, typically the artist would add some other things to flesh out the art more, or to put it another way, detailing the art. Once finished, the full spectrum of the chosen colors is applied for the final phase. And with that, the process of creating a game art is done. While this is true for making normal drawings, the phase where the artist seeks approval is not really abided if it's a personal drawing or basically without any intentions to be used by another party other than the artist.

Another important part is the storytelling. Storytelling is a form of describing something, be it an event or an important moment, through various means such as theatrics, improves or embellishment (Bavelier, Green, Pouget, \& Schrater, 2012). Crucial points in storytelling (and the story it's telling) includes: plot, characters, and narrative point of view (Kee, 2011). Also, storytelling can be referred to, specifically, oral storytelling. Also, in a looser term, for techniques used to display the narrative of a story in other medias.

Video game, in retrospect of the said definition of storytelling is a part of what modern culture calls interactive storytelling. Interactive storytelling is defined as a form of digital entertainment in which the story is not pre-determined. In a short summary, interactive storytelling allows for the user to experience a unique story based on their interaction with the story world, in which the author had already 
established the setting, characters, and situation for the user to be involved with (Bavelier, Green, Pouget, \& Schrater, 2012).

\section{Related Material}

\section{History of Indonesia}

The history of Indonesia that is the main topic of this paper is the period between just before the Japanese occupation of Indonesia (1942-1945) and the Declaration of Indonesia's Independence (1945). This will serve as a short explanation on what happened during that period and a short summary of the presence of the Dutch before the Japanese came.

For three and a half centuries, Indonesia, back then known as the Dutch East Indies, was ruled under the Netherlands. But in the early $20^{\text {th }}$ Century, the people experienced what will be known as the National Awakening, where various underground movements from various ideologies formed by the people that benefited from the Education Reforms by the Royal Netherlands Government. However, they were heavily suppressed by the colonial government back then. Then, in the year 1939, World War 2 broke out in Europe. The Royal Netherlands Government was exiled after they lost to the German Reich. Coupled with the Japanese Invasion of the Dutch East Indies that occurred in late 1941 and ended in the Japanese victory in early 1942, also helped to accelerate the movements to even get close to realize the idea of independence.

But in the three years of Japanese Occupation of the Dutch East Indies, it was nothing short of brutal \& inhumane. Many were forced to work hard labor, also known as romusha, and they were not limited to work in Indonesia. Of those that were sent to the overseas territories of the Greater Japanese Empire, only $20 \%$ of the total tens of thousands that managed to even return to Indonesia. This is not even mentioning the many woman that were forced into prostitution for the Japanese army. However, while they eventually forbidding any mention of Indonesia or the use of the National Flag, they formed many organizations that eventually helped the Indonesians during the Indonesian National Revolution that started in 1945 after their declaration of Independence to 1949.

While the Japanese never intended to give Indonesians their independence, opting to annex them into the Greater Japanese Empire instead, the turn in the tide of the Pacific front in the $2^{\text {nd }}$ World War prompted them to give Indonesians "false" hope of independence, hoping that they would be able to help defend the Japanese Empire from the Allied Forces. However, after the subsequent surrender of the Empire in August 1945, they tried to keep the status quo as part of the agreement. However, by then, the Indonesians had already prepared themselves for the Declaration of Independence and the entire nation was already in the full swing of the National Awakening movement.

\section{Literature Review}

As for the literature study, from several conclusions that I have made, making 
games for a historical game that's also educational, requires several things for it to succeed. It includes, but not limited to:

\subsection{Storytelling}

In storytelling of a video game, the player is put into the boots of the character, as in from the point of view of the character they're controlling at the time (Bavelier, Green, Pouget, \& Schrater, 2012). Depending on what type of game it is, it may feature the view of the whole situation depicted only from their character, the protagonist so to speak, as the main source of point of view. There are also other games that allows changing to different characters and experience a different point of view compared to the other characters that are playable in the game. Their motivations, their opinions, and other things that expresses the differences between each character can be experienced in these kind of games (example: Grand Theft Auto 5, Telltale's The Walking Dead series).

\subsection{Narration}

How the narration will be carried out, be it directly said in the dialogue or implied in the events of the game but no mention of it in the dialogues (Kee, 2011). Directly saying it in the dialogue, for example, in Call of Duty: World at War, our character gets explained by Viktor Reznov about what happened after the battle of Stalingrad when he rescued us from captivity by Nazi soldiers, where the Nazis were close to capturing Moscow but failed and now the Soviet Union is on the offensive.

\subsection{Genre}

The choice of genre for the game affects what kind of player base it will have, and audiences that may, in the future, become a part of the player base of the game (Kee, 2011). It also affects the development of the game, since the gameplay mechanics will be affected in some areas. For example, if the game in development's chosen genre is a Shooter, then the first crowd that will be attracted to it are fans of the genre (i.e. FPS gamers, Light-gun arcade lovers, TPS players). Then we expand to what kind of Shooter it is, will it be a computer/console game, or a light-gun arcade (arcade machine with gun replicas connected to the machine as the controller). This will heavily affect the gameplay mechanism, as typically, arcade games are linear in terms of story progression, while computer/console games allow for branching stories that can have multiple endings or multiple choices for progression of the story.

\subsection{Example}

Games that are chosen to be the example of what the game in development could be are also important. It helps in forming the image of what kind of game it would be, for the gamers (Kee, 2011). But for the developer, it helps in making the game, since they got hints from the example that they chose, and they may 
add or subtract things from the game they're developing.

\subsection{Content}

The items represented in the game, including the weapons, armor, vehicles (if any) will also affect the immersion levels as part of the content in the game. The content of the game itself would be affected by what genre it's chosen and kind of game it is. If it's depicting historical events with the intention of showing an accurate depiction of said events, then the items that will be featured and used in the game must match the period of the historical event it's depicting (Kee, 2011). For example, if it's set in World War 2, then the guns used by the Allied Forces at least must use ones that are produced from before or during the War.

\subsection{Depth of Immersion during Gameplay}

While the title says it all, the rundown of this is the amount of immersion that the player can experience in the game. Immersion is basically the state in which one is involved in the event or action. The amount of content in the game will affect the immersion levels of the players. They include things like the story (as in the mission), the side stories (in which it expands the world, gives the game the world-building), the setting (helps in explaining the events that preceded the main story in which it may or may not have lead the whole thing to the current storyline of the game), and the contents of the game (Spence \& Feng, 2010).

\section{Research Method}

The chosen method for this research is divided into two of the following methods: Sample analysis and Literature study. Sample analysis involves analyzing two (or more) different samples. The criteria for the analysis include what art style it uses, what color(s) were used in the drawings, why it falls into that art style, and the artist's point of view. While the point of view of the artist based on just the art style used in making the drawings could be biased, it will still be included for the sake of argument and description. There are around six art styles that are commonly used. The following are the short summary of each art styles:

- Realistic: Refers to the fact that it's highly detailed, so much that it's almost real.

- Hyper-Real: This is like a step above Realistic. This refers to the fact that one can even see microscopic objects that are usually impossible in the real world without the usage of Microscope.

- Simplified: Usually, it only shows the essentials that really tells the message/story that the creator wants to convey.

- Stylized: Very personalized \& doesn't adhere much to realism.

- Graphic: Very explicit in showing content.

- Imaginative: Very distancing from reality, to only imagination.

While there are several instances where an illustration uses a hybrid art style, or a mix between two art styles (maybe even more than two), in general, they 
tend to lean more towards one than the other. Hence, classifying such cases as simply one style would be inaccurate.

As for the selection of colors, the chosen color(s) each have a different meaning, if one were to look it from a psychological stance (Elliot \& Maier, 2014). For example: Red symbolizes love, White represents holy, Yellow means warning, Black means death, and Green represents Hope. These are the few of the many selection of colors, but in general, they're a part of these colors, though each have a different meaning compared to the generalized grouping of said colors. And the stimuli of each have different effects on the viewers.

The sample(s) used in the Sample Analysis are taken from several games or other sources. The following are the list of sources of the used samples:

- Valiant Hearts

- Battlefield 1

- That Dragon, Cancer

- Wolfenstein 2: The New Colossus

- MineCraft

The second method follows literature study. The purpose of the literature study is to see if the results from differing methods by other researchers have yielded any positive results in the motivations of the students in learning of the subjects chosen by those researchers and if the games helps in teaching the subjects in question. This literature study will use various research paper from various studies conducted, and they may or may not have direct connections to the subject of this research paper. However, with certainty, they will fall into one (or all) of the following aspects:

- Game Art

- Example

- Gameplay Experience (Depths of Immersion, Content)

- Storytelling (or Narration)

- Genre

Each of these aspects affects the longevity of a game, typically whether people would consider it to have replayability value or not, and if the intended goal of the game's creation has been achieved or not (Patton, 2016). In this case, to see if the game manages to help the students in the study of a subject, while not lacking in these aspects and provides boost to the motivation of the students in studying the said subject (Squire, 2008). As to the purpose of the literature study, it's to give some explanation on player's reaction/behavior during gameplay, in which each aspect has a different effect on the player's experience during gaming sessions, thus allowing for a degree of understanding when discussing the sample and its sources.

\section{Comparison \& Discussion of Samples}

\subsection{First Sample}

From the Figure 1, the color palette presented here is bright, yet it has some 

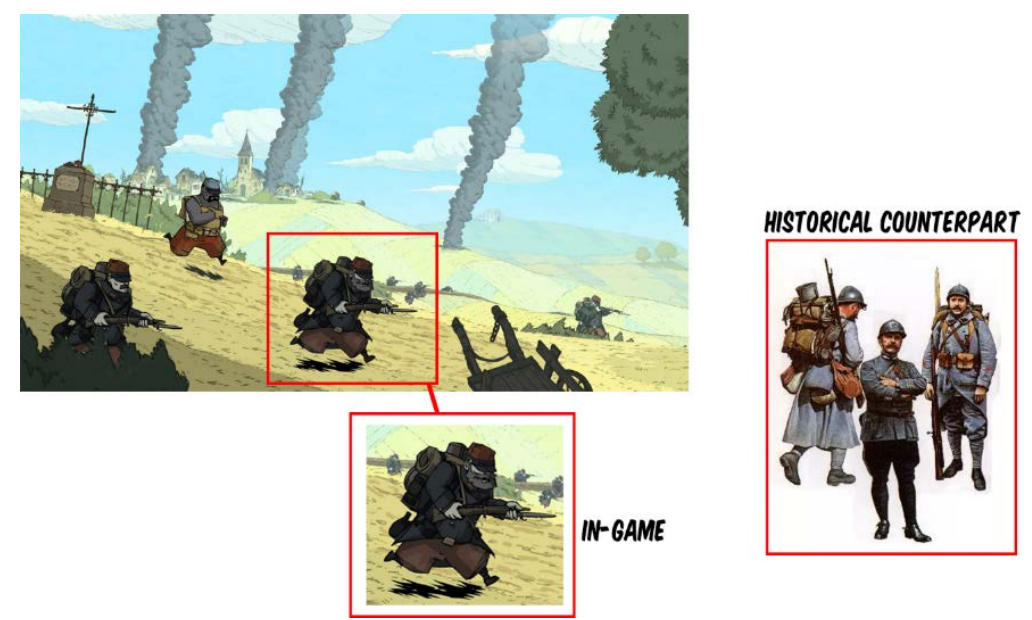

Figure 1. Example from Valiant Hearts, an example of a Stylized, along with the historical comparison.

dark tones in it. While the weather looked bright, the atmosphere that's being displayed shows a grim one. Soldiers running down a hill to reach their enemy, while in the background one can see smokes rising to the sky, the aftermath of either artillery strikes or air bombardment. The color of their uniform is dark, despite being in a bright day, while the smoke in the background isn't enough to darken the sky in the background, yet it shows that the damage done to the location is quite significant. This shows that despite the somewhat bright background (if one disregards the smoke), the depicted event isn't so bright, emphasizing the atmosphere \& the feel of the battlefield, with the sheer desperation to drive back the enemies. The atmosphere, so to speak, was filled with a heavy pressure, a tense air so to speak. The defenders in question, the French, were struggling against the invading German army. Lacking in several things (from the chosen sample seems to be lack in superiority and artillery support), they were forced to contend with the German army in a manner that's, to be blunt, suicidal. The desperation of the French soldiers depicted were also due to these things, and the seemingly unstoppable advance of the German army further affected the morale of the men and the decisions made by the higher-ups in the French's chain of command.

And from the chosen art style, it's considered to be Stylized. The reason for that is because while it has a great amount of detail in it, it's not exactly realistic, starting with the proportion of the body of the soldiers. A soldier with that kind of body proportion would not even qualify to enlist in the army, unless they're militias. However, the equipment shown in the picture clearly shows that they aren't militias. They're the army regulars, or in other words, the average soldiers employed in the army. And in biology terms, they must be fit, able to carry their equipment for a prolonged period and sprint for a set amount of time. From the estimated weight of the soldiers based just on this picture, they'd be considered overweight. Although, to the credit of the artist, the equipment \& uniform depicted in the sample were close enough when compared to their historical coun- 
terpart, which was the French Army during the First World War. And since they look like they're able to run just fine with that amount of body weight \& all that equipment, the style of the art in this sample could be classified as Stylized.

\subsection{Second Sample}

Meanwhile, from Figure 2, the amount of color palette displayed were close enough to the original source material. Although there were no comparisons for the picture of the building during wartime (the Japanese Invasion of Dutch East-Indies, World War 2), from the pictures that shows it before the war, it hasn't changed much, with the exception being its surroundings. The focus of the colors used are more towards historical accuracy than realism in terms of being affected by the combat occurring at the surrounding location.

The art style is somewhat between realistic and simple. While it is obvious that while it is not that detailed, it tried to follow the original source material. The visible grills on the window shutters, while not accurate to the real-life counterpart, it emulates it good enough to represent it in the game. And the short stairs, while not pointed out in the comparison above, it is also somewhat visible that it is also somewhat faithfully recreated in the rendering. Although, the same cannot be said for the roof tiles of the building, since it is not drawn in the rendering.

\subsection{Third Sample}

From Figure 3, one can see that the rendering of the rifle is, for all intents and purposes, almost like its real-life counterpart. While it may have been due to it being modeled in $3 \mathrm{D}$, and that the texture (or even the whole rifle itself) may have been directly scanned from the real object, there's no denying that this form of art style is, without a doubt, Realistic.

The reason it being qualified is from the amount of detail depicted: the wood lines on the body of the rifle, the shine from the reflection of the light off the rifle's iron parts.

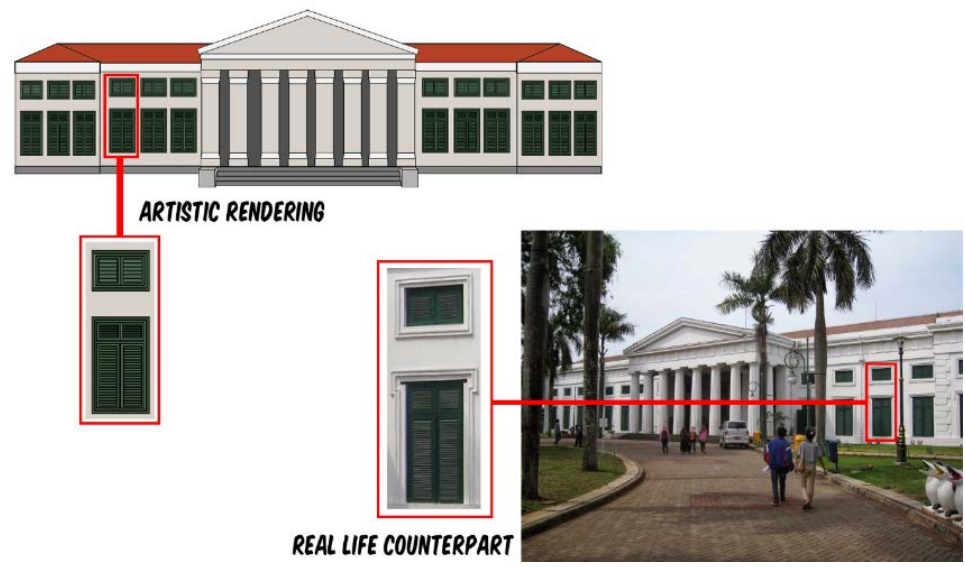

Figure 2. Comparison between the artistic rendering ${ }^{\star} \&$ real-life counterpart of the $\mathrm{Mu}$ seum of Arts \& Crafts, formerly the Batavia Colonial Court Building. ${ }^{*}$ The rendering is from an unpublished, private game. Caution of bias is advised. 


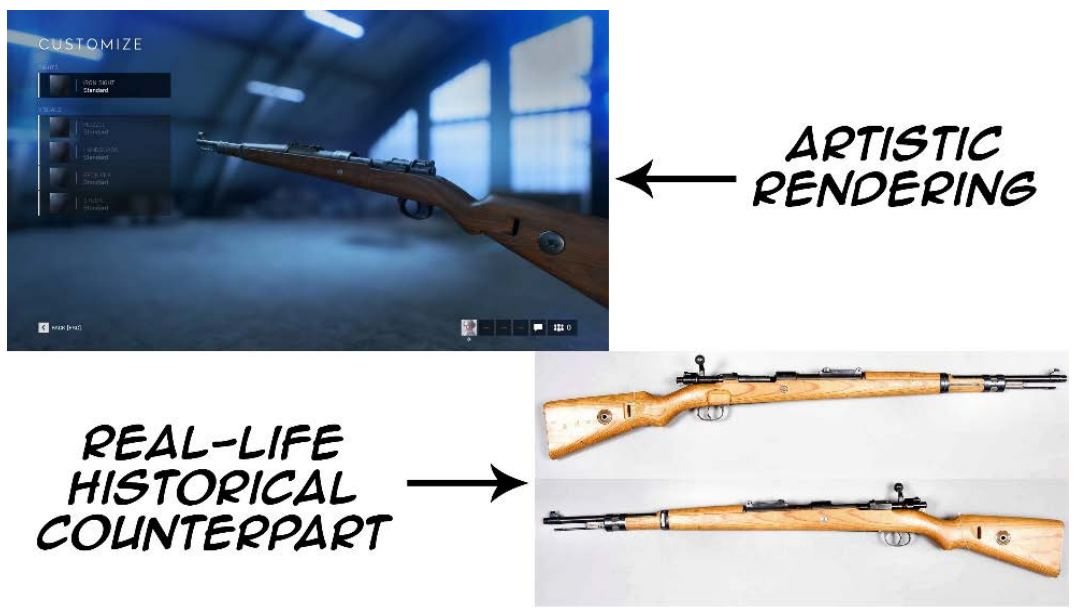

Figure 3. Comparison between the artistic rendering \& real-life counterpart of the infamous Kar98k Bolt-Action Rifle, taken from Battlefield 1.

While it could be counted as Hyper-realistic, although it's not there yet due to the limitations of the game engine used to render the asset, although it's close.

\subsection{Fourth Sample}

As depicted by Figure 4, the art style used in is the Simplified style. As to why it's considered as Simplified is due to the lack of details in the depicted scene.

Although, this is not to say that it's random, since that would be considered as Imaginative at that point. However, that's not the case since it still adheres to reality in the shapes of the actors in the scene.

However, the lack of the eyes or the texture of the skin on the actors, or the lack of ripples displayed on the surface of the water or the follicles of the grass, emphasizes that the art is of less importance in priority compared to the story being depicted.

\subsection{Fifth Sample}

For the art style used in Figure 5, it's already visible in being Realistic. However, it's also Graphic. The reason for it to be considered as Graphic being the display of gore that's uncensored, and extreme violence. With the amount of detail being displayed in the scene, such as the grills of the walkway, the SS insignia on the collars, and the texture of the skin, it can also be considered to fall into the style of Realistic.

In this sample, the main character, controlled by the player, is cutting the throat of a Nazi officer with a Combat Knife. The wound on the neck, blood pouring out of the knife wound, and the amount of violence shown qualifies the sample as being Graphic.

\subsection{Sixth Sample}

As seen in Figure 6, the art style used in this sample is Imaginative. The reason for it being Imaginative being the absurdity of a world in the shape of a cube, 


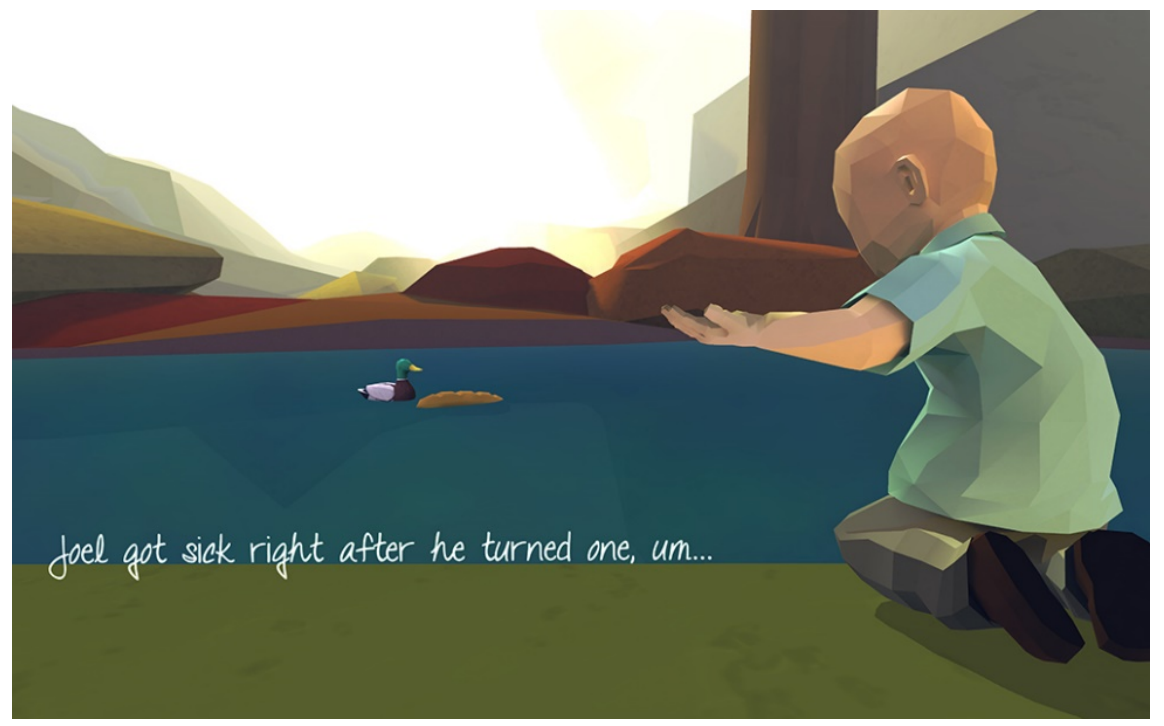

Figure 4. A Screenshot taken from the game That Dragon, Cancer.

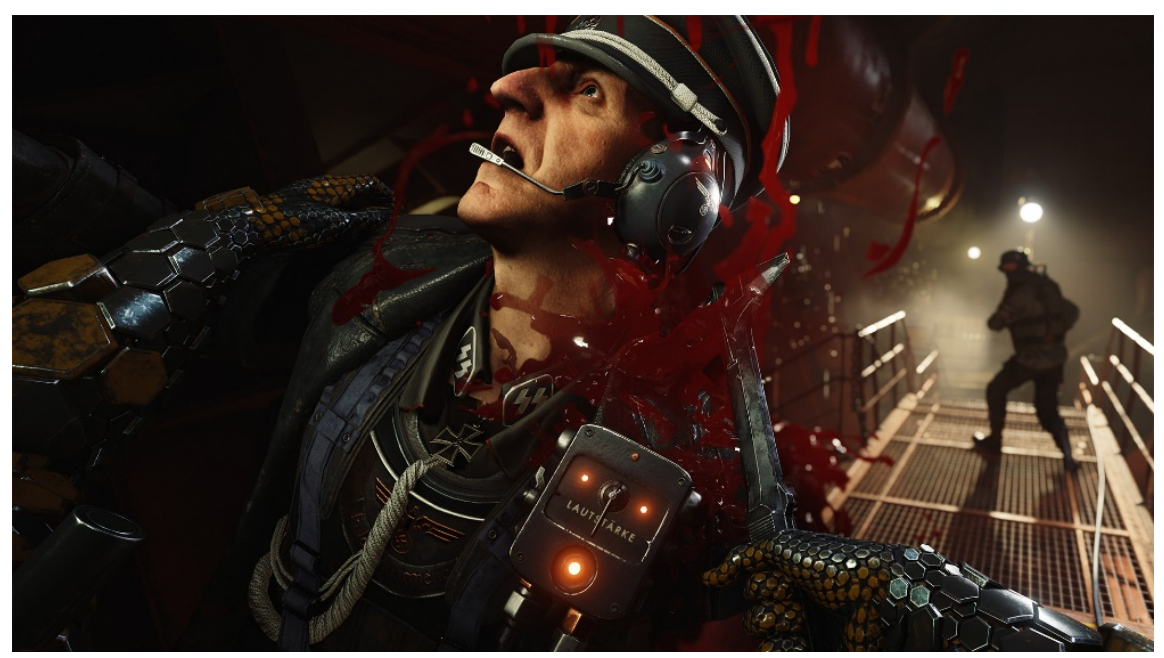

Figure 5. A Screenshot taken from the game Wolfenstein 2: The New Colossus.

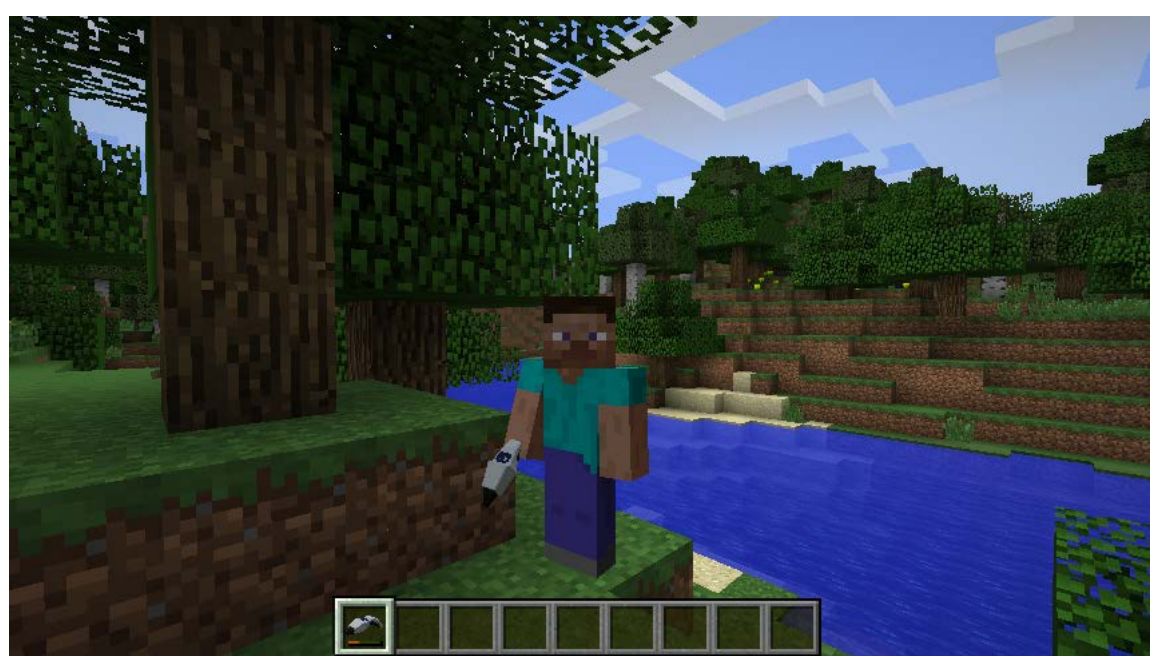

Figure 6. A Screenshot taken during gameplay in MineCraft. 
with everything in it being in cubes or a structure made of cubes. Also, since somehow, people, animals, and other living things in this game world could run, despite being very symmetric and not stumbling when attempting to move around, it means that it doesn't adhere to the laws of physics, further emphasizing that it's a game with an Imaginative-style art.

This concludes the data analysis part, and what I can gather from samples.

\section{Conclusion}

From the data analysis, one can conclude that the art style used in a drawing shows the artist's point of view about a situation or things in general. The color(s) used also reflects on what light does he/she views things. In short, it shows the personality of the artist. Also, the artist's capability to depict an event that includes the characters, background etc. in the game would also be visible, based on the accuracy on the details of said requirements, and whether the chosen art style \& color palette matches what the developers wanted to convey.

Meanwhile, from the literature review, one can draw the conclusion that storytelling in video games can affect major aspects of the game experience as whole: it affects the genre the game will be in, the kind of narration it will use to tell the story, the content that will be included, and how deep the immersion the game will have (Padilla-Zea, Gutierrez, Lopes-Arcos, Abad-Arranz, \& Padrewski, 2014).

Moreover, due to the limitation presented during the process of research, which includes the lack of references in regards of research on game art and the lack of the writer's experience in conducting the research, the results that have been garnered from the research were less than proper, or lacking, to put it in a perspective. On matters such as the psychology of the colors used in game arts \& what effects it has on the players, be it during gaming sessions or after, warrants a more in-depth look into the topic, and by a more qualified person in this field of study.

In summary, the art style of the game is influenced by the genre, storytelling method, and various other factors. As to its effects on whether it has an impact on the players in terms for educational video games, it depends on the overall content that the developers would put into the game, and whether the game itself could fulfill the required criteria for the "replayability" that will affect the survival of the game after it's launched.

\section{Conflicts of Interest}

The author declares no conflicts of interest regarding the publication of this paper.

\section{References}

Apperley, T. H. (2013). The Body of the Gamer: Game Art and Gestural Excess. Digital Creativity, 24, 145-156. https://doi.org/10.1080/14626268.2013.808967

Bavelier, D., Green, C. S., Pouget, A., \& Schrater, P. (2012). Brain Plasticity through the 
Life Span: Learning to Learn and Action Video Games. Annual Reviews of Neuroscience, 35, 1-83. https://doi.org/10.1146/annurev-neuro-060909-152832

Charsky, D., \& Ressler, W. (2011). "Games Are Made for Fun”: Lessons on the Effects of Concept Maps in the Classroom Use of Computer Games. Computers and Education, 56, 604-615. https://doi.org/10.1016/j.compedu.2010.10.001

Elliot, A. J., \& Maier, M. A. (2014). Color Psychology: Effects of Perceiving Color on Psychological Functioning in Humans. Annual Review of Psychology, 65, 95-120. https://doi.org/10.1146/annurev-psych-010213-115035

Erhel, S., \& Jamet, E. (2013). Digital Game-Based Learning: Impact of Instructions and Feedback on Motivation and Learning Effectiveness. Computers and Education, 67, 156-167. https://doi.org/10.1016/j.compedu.2013.02.019

Kee, K. (2011). Computerized History Games: Narrative Options. Simulation and Gaming, 42, 423-440. https://doi.org/10.1177/1046878108325441

Padilla-Zea, N., Gutierrez, F. L., Lopez-Arcos, J. R., Abad-Arranz, A., \& Padrewski, P. (2014). Modelling Storytelling to Be Used in Educational Video Games. Computers in Human Behavior, 31, 463-474. https://doi.org/10.1016/j.chb.2013.04.020

Patton, R. M. (2016). Games as an Artistic Medium: Investigating Complexity Thinking in Game-Based Art Pedagogy. Studies in Art Education, 3541, 35-50.

Peirce, N., Conlan, O., \& Wade, V. (2008). Adaptive Educational Games: Proving Non-Invasive Personalized Learning Experiences. Proceedings-2nd IEEE International Conference on Digital Games and Intelligent Toy Enhanced Learning, DIGITEL 2008, 28-35. https://doi.org/10.1109/DIGITEL.2008.30

Spence, I., \& Feng, J. (2010). Video Games and Spatial Cognition. Review of General Psychology, 14, 92-104. https://doi.org/10.1037/a0019491

Squire, K. D. (2008). Video Games and Education: Designing Learning Systems for an Interactive Age. Educational Technology Magazine: The Magazine for Managers of Change in Education, 48, 17-26.

Yue, W. S., \& Zin, N. A. M. (2009). Usability Evaluation for History Educational Games. Proceedings of the 2nd International Conference on Interaction Science Information Technology, Culture and Human-ICIS '09, 1009-1025. 